\title{
Risk aversion and inequity aversion in demand for unemployment benefits
}

\author{
Peter G. Backus ${ }^{1,2}$ • Alejandro Esteller-Moré ${ }^{2,3}$
}

Published online: 29 July 2016

(C) The Author(s) 2016. This article is published with open access at Springerlink.com

\begin{abstract}
This paper is an empirical study of what motivates net contributors to support redistributive policies. While studies in the area have tended to consider broad measures of inequality and support for redistribution in general, we focus on a single, salient relationship between local unemployment rates and demand for spending on unemployment benefits. Using a particularity of the Spanish labour market, we estimate how workers' stated preferences for unemployment benefits spending respond to changes in the local unemployment rate. We then decompose this response into the part explained by risk aversion, and thus demand for insurance, and the part explained by inequity aversion. Our results suggest that increases in local unemployment rates lead to increased demand by workers for unemployment benefits spending. Moreover, our results are consistent with an insurance motive driving this relationship but provide little support for inequity aversion. Our results suggest that studies of the relationship between inequality and demand for redistribution might benefit from considering both the source and measure of the inequality and the instrument of redistribution.
\end{abstract}

Keywords Preferences for redistribution - Unemployment · Unemployment benefits JEL Classification D64 $\cdot$ H53 $\cdot$ H77

\footnotetext{
$凶 \quad$ Peter G. Backus peter.backus@manchester.ac.uk

1 University of Manchester, Oxford Road, M13 9PL Manchester, UK

2 Institut d'Economia de Barcelona (IEB), c/ John M. Keynes, 1-11, 08034 Barcelona, Spain

3 Facultat d'Economia i Empresa, Universitat de Barcelona, c/ John M. Keynes, 1-11, 08034 Barcelona, Spain
} 


\section{Introduction}

One of the main roles of modern governments is the redistribution of income. There is a growing literature in economics which seeks to understand just why it is that net contributors to a redistributive system support it (Boeri et al. 2001). Nearly every OECD country has a degree of progressiveness in their income tax system (OECD 2008 , p. 112) designed to redistribute income from the better off to the worse off indicating a preference among the population for redistribution. Some of the research in this area has shown that the source of the inequality can play a role in determining the degree to which people support redistribution. However, much of the literature on redistributive preferences has focused on a general conception of these preferences and subsequent demand for redistribution. We consider redistributive preferences within the context of a single redistributive instrument: unemployment benefits.

In general, the specific policy instrument used to redress inequality has been ignored when studying people's preferences for redistribution. But the policy instrument is an essential part of the question of redistributive preferences. Piketty (1996) notes "individuals might well share the same 'values' as far as distributive justice is concerned, but...they disagree about the way actual inequality between individuals is generated" (p. 8). Where people disagree about the source of inequality, they will likely also disagree about the policy best suited to redress the inequality. It is therefore essential to consider redistributive preferences within the context of a particular instrument since the underlying reasons for why a person supports redistribution might vary from one instrument, say transfers to the poor, to another, say unemployment benefits.

In this paper, we examine the relationship between changes in the income distribution, as measured by changes to the unemployment rate, and stated preferences for unemployment benefits. Economists have identified a number of potential motivations underlying support for redistribution like demand for insurance and inequity aversion, and Alesina and Giuliano (2011) note that the empirical disentanglement of these motives is difficult, albeit not 'fatally' so. We address this challenge directly and seek to contribute to the empirical work on redistributive preferences (e.g. Dahlberg et al. 2012; Luttmer and Singhal 2011; Guillaud 2013), using a newly constructed data set and a particularity of the Spanish labour market whereby public sector workers enjoy nearly inviolable job security. We estimate the effect of individual unemployment risk and of the local unemployment rate on workers' declared preferences for redistribution via one instrument: unemployment benefits. We then decompose that effect into the part explained by risk aversion and demand for insurance and the part explained by inequity aversion. Our results suggest that in this case it is demand for insurance that drives declared preferences for redistribution. We find no evidence that inequity aversion plays a role in determining people's preferences for redistribution via unemployment benefits.

Studying the unemployment rate/benefits relationship may provide deeper insight into preferences for redistribution given the saliency of the two. Gimpelson and Treisman (2015) find that there are systematic differences between the perceived and actual level of income inequality when considering income shares. Kuziemko et al. (2015) argue that demand for general redistribution might not be too intense because people are unlikely to be aware of the level and changes in some more general inequality 
metric. Atkinson (2015) also raises the issue of the saliency of changes in income distributions. He notes that a change in the Gini of at least $3 \%$ points may be necessary to be salient. Such a large change generally takes years if not decades to be realised, perhaps reducing the salience of the overall change. Ashok et al. (2016) use broad questions about redistributive preferences ${ }^{1}$ and inequality ${ }^{2}$ and find little evidence that rising inequality in the USA has led to increased demand for redistribution over the past 40 years. It is arguable that the absence of any effect in their study is due to the in-salient nature of changes to measures like the Gini or percentile ratios. The level of unemployment, however, is a clearly visible, often reported and simple to comprehend variable making it more likely that individuals will recognise any change and respond, assuming that they respond at all. Moreover, in the case of unemployment, the instrument (unemployment benefits) and the target of the redistribution (the unemployed) are inextricably linked making it simpler to analyse the relationship between the two.

While focusing on unemployment goes some way towards addressing issues of salience, it does so at the cost of generality. Our results tell us something about the relationship between unemployment and demand for redistribution via unemployment benefits but may tell us little about how demand for redistribution via some other instrument will respond to changes in the income distribution. Nor are our findings on the underlying motives necessarily generalisable to other forms of redistribution. The unemployment rate/benefits nexus is distinct from more general conceptions of redistribution in some important ways. Unemployment benefits are designed primarily to smooth consumption over time. Moreover, the insurance function of unemployment benefits is likely to be more salient than its redistributive function. Unemployment benefits are often referred to as unemployment insurance, though there is indeed a redistributive component to unemployment benefits. As Boadway and Oswald (1983) argue, "casual observation suggests that policy makers have in mind redistribution of income as at least one rationale for unemployment insurance" (p. 195). Moreover, the unemployment rate and broader measures of income inequality are linked (Bover et al. 2002; Castells-Quintana and Royuela 2012).

This lack of generality may be a feature of our setting as well as a shortcoming. Disagreement over the manner in which income is redistributed is found in McCall and Kentworthy (2009) who show that while people object to increasing inequality and support government intervention to address the problem, they disagree about the appropriate instrument to do so. Thus, the relative importance of different motives underlying redistributive preferences may depend on the choice of redistributive instrument under consideration (Husted 1990). General survey questions about the role of government in the redistribution of income may neglect heterogeneity of the preferences over the source of inequality and the instrument of redistribution and may therefore fail to measure the relationship of interest. Again, we pay a cost of 'generality', but gain an advantage insofar as our conclusions apply to a particular policy in a clear and direct way. In summary, using unemployment and unemployment benefits

\footnotetext{
1 Using, for example, the question from the US General Social Survey that asks respondents if they agree with the statement that "The government should guarantee basic standard of living."

2 They use changes in the income share of the top $1 \%$ of earners.
} 
to study redistributive preferences allows us to focus on a single, salient measure of inequality and a specific, well-defined instrument through which it is redressed.

The rest of the paper is as follows. Section 2, we briefly review the literature and outline a theoretical framework to aid us in interpreting our results. In Sect. 3, we describe our data and discuss our identification strategy. Results are discussed in Sect. 4. Conclusions are drawn in Sect. 5.

\section{Preferences for redistribution}

Economists have identified different reasons why net contributors might support redistributive policies. First, demand for insurance may underlie preferences for redistribution. Net contributors may support redistributive polices in case they themselves become net recipients at some point. This explanation fits comfortably with standard notions of economic self-interest and redistribution as insurance has been studied extensively by economists (Casamatta et al. 2000; Moene and Wallerstein 2001; Donder and Hindricks 2003; Zweifel 2013). However, demand for insurance is insufficient to fully describe preferences for redistribution (Fong 2001).

Economists have therefore considered alternative explanations for redistributive preferences whereby net contributors derive utility from the welfare of others, directly or indirectly. People might derive utility from the welfare of others due to altruism (Rueda and Pontusson 2010). Alternatively, people might display self-interest of the 'enlightened' variety, which would also require an 'other-regarding' component to preferences. ${ }^{3}$ Such 'other-regarding' preferences (Cooper and Kagel 2013) would present themselves as a form of inequity aversion (Fehr and Schmidt 1999), i.e. increased inequality would lead people to demand more redistribution. We remain agnostic about why people might be concerned with the welfare of others and focus instead on whether we see evidence of inequity aversion in preferences for redistribution via unemployment benefits. We therefore consider a inequity aversion motive in addition to the insurance (risk aversion) motive. ${ }^{4}$

Our primary interest is in empirically estimating the responsiveness of declared preferences of workers for unemployment benefits spending to changes in the local unemployment rate. To aid in the interpretation of our results, we outline a simple theoretical model. We assume a continuum of agents normalised to 1. Of these agents,

\footnotetext{
${ }^{3}$ For example, Alesina and Giuliano (2011) note that "the level of inequality may affect crime and some people may be more or less subject to the risk of criminal activities" (p. 1). So net contributors may be concerned with the level of inequality or the welfare of the poor but only insofar as it reduces the exposure of the contributor to crime.

4 Preferences may also have a fixed component. For example, individual beliefs have been shown to be important. Such beliefs likely exhibit a degree of persistence. For example, religious beliefs are found to be important (Neustadt 2011) in the formation of redistributive preferences. An individual's beliefs about potential socio-economic mobility (Piketty 1995) and/or the relative roles of 'luck' and effort in determining outcomes (Fong 2001) have also been shown to be predictive of that individual's preferences for redistribution. While such beliefs can play a role in determining the level of demand for redistribution via unemployment benefits, our interest is in the responsiveness of this demand to changes in the level of unemployment, so any fixed component of preferences will drop out in the derivative. We therefore exclude fixed beliefs from our analysis and focus instead on the roles of risk and inequity aversion.
} 
share $(1-u)$ will be employed and $u$ will be unemployed and eligible for unemployment benefits where $0<u<1$. We are interested in the preferences of the employed agents. All employed agents earn the same (gross) labour income, $y$, and consume $c_{e}=(1-t) y$, where $t$ is a payroll tax used to fund the unemployment benefit system and $0<t<1 .^{5}$ Unemployed agents receive benefits, which allows them to consume $c_{u}=\beta y$, where $\beta$ is the replacement rate, $0 \leq \beta<(1-t)$. That is, the effect of the choice variable, $t$, on the consumption of the unemployed is realised via $\beta$. Agent $i$ derives utility from her own consumption, and we allow her to possibly derive utility from the consumption of unemployed people as well, where $\theta_{i} \geq 0$ captures the degree to which $i$ derives utility from $j$ 's consumption.

The timing of the model is as follows. We impose a veil of ignorance (Rawls 1971) on agents such that, ex ante, they observe $x_{i}$, a vector of $i$ 's employment characteristics (e.g. education, occupation, industry of employment and sector of employment) and know that share $u$ of all agents will be unemployed. The veil conceals the agents' ex post employment status, although each knows the probability that she will be unemployed, $p_{i}=p_{i}\left(x_{i}, u\right)$, where $\partial p_{i} / \partial u \geq 0$ and $\bar{p}=u$. Ex ante, agents declare their preferred level of redistribution via unemployment benefits, $t_{i}^{*}$, given $x_{i}, u$ and thus $p_{i}$. While this set-up is highly artificial, it provides an analogue to the situation where workers have a preferred level of benefits spending in the face of uncertainty about their continued employment and the prevailing level of unemployment.

The expected utility of agent $i$ is:

$$
E\left[U_{i}\right] \equiv\left(1-p_{i}\right) U\left(c_{e}^{i}\right)+p_{i} U\left(c_{u}^{i}\right)+\theta_{i} \tilde{U}\left(c_{u}^{j}\right)
$$

where the first term is the utility $i$ derives from her own consumption if she is employed, the second term is the utility $i$ derives from consumption if she is unemployed and the third term is the utility $i$ derives from the consumption of others when they are unemployed.

The budget constraint of the unemployment benefit system is:

$$
\operatorname{ty}(1-u)=\beta y u
$$

Rearranging yields

$$
\frac{1-u}{u} t=\beta
$$

\footnotetext{
5 Until 2009, unemployment benefits were essentially fully funded out of social security contributions, but since then, due to the severity of the crisis and the high unemployment rate, those contributions fund about $50 \%$ of the unemployment benefit system. To make up the difference, the central government transfers resources - funded out of general taxes. For simplicity, though, we use a single tax to fund the unemployment benefits system in our model.
} 
where $\partial c_{u} / \partial t>0$ and $\partial c_{u} / \partial u<0 .{ }^{6}$ That is, $\beta$ varies with $t$ and $u$ to ensure the budget constraint holds with equality.

Substituting Eq. 3 into Eq. 1 and maximising it with respect to $t$ yield the FOC:

$$
\begin{gathered}
\text { Marginal benefit } \\
t_{i}^{*}: \frac{1-u}{u}\left[p_{i} U_{u}^{\prime}+\theta_{i} \tilde{U}_{u}^{\prime}\right]=\begin{array}{c}
\text { Marginal cost } \\
\left(1-p_{i}\right) U_{e}^{\prime}
\end{array}
\end{gathered}
$$

where primes stand for partial derivatives of a single variable, and assume utility is an increasing, concave function of consumption such that, $U^{\prime \prime}($. $)<0<U^{\prime}$ (.). ${ }^{7} \mathrm{We}$ assume that the marginal utility from $i$ 's own consumption when unemployed, $U_{u}^{\prime}$, is at least as large as the marginal utility $i$ derives from $j$ 's consumption when $j$ is unemployed, i.e. $U_{u}^{\prime} \geq \tilde{U}_{u}^{\prime}>0$.

We then totally differentiate Eq. 4 with respect to $u$, and substitute the Eq. 4 into it, yielding:

$$
\frac{\mathrm{d} t_{i}^{*}}{\mathrm{~d} u}=\frac{t_{i}^{*}}{u}\left\{\frac{(1-u) \varepsilon_{p_{i, u}}^{i}\left[U_{u}^{\prime}+\theta_{i} \tilde{U}_{u}^{\prime}\right]+p_{i} U_{u}^{\prime}\left[R A_{i}-1\right]+\theta_{i} \tilde{U}_{u}^{\prime}\left[I A_{i}-1\right]}{(1-u)\left[\left(p_{i} U_{u}^{\prime} R A+\theta_{i} \tilde{U}_{u}^{\prime} I A\right]\right.}\right\} \geq 0
$$

where $\varepsilon_{p_{i}, u}^{i} \equiv \frac{\partial p_{i}}{\partial u} \frac{u}{p_{i}} \geq 0$ is the sensitivity of $i$ 's own probability of employment to changes in $u, R A \equiv-\frac{U_{u}^{\prime \prime}}{U_{u}^{\prime}} c_{u}^{i} \geq 0$ is a measure of relative 'risk aversion' á la ArrowPratt (Arrow 1965) and, similarly, $I A \equiv-\frac{\tilde{U}^{\prime \prime}{ }_{u}}{\tilde{U}_{u}^{\prime}} c_{u}^{j} \geq 0$ accounts for $i$ 's 'inequality aversion' (Atkinson 1970). Note that the sign of Eq. 5 is unambiguously non-negative when $I A>1$ and $R A>1$ (Meyer and Meyer 2005).

The first two terms in the numerator $\left((1-u) \varepsilon_{p_{i, u}}^{i}\left[U_{u}^{\prime}+\theta_{i} \tilde{U}_{u}^{\prime}\right]+p_{i} U_{u}^{\prime}[R A-1]\right)$ capture the insurance motive. The more risk averse $i$ is, the greater her demand for insurance. The last term $\left(\theta_{i} \tilde{U}_{u}^{\prime}[I A-1]\right)$ describes the inequity aversion component which is a function of both the degree to which $i$ is concerned with the welfare of others (i.e. other-regarding), $\theta_{i}$, and how averse they are to inequality, $I A_{i}$ (i.e. the larger the increase in $i$ 's marginal utility from changes to $c_{u}^{j}$, again due to the binding budget constraint of the system).

Our interest is not in the determinants of the level $t^{*}$ but in estimating an analogue of $\frac{\mathrm{d} t_{i}^{*}}{\mathrm{~d} u}$, the responsiveness of $t^{*}$ to changes in $u$, and to disentangle the risk and inequity aversion components underlying the effect. Empirically, such disentanglement requires one of the motives to be held constant. The degree to which agents are

\footnotetext{
${ }^{6}$ Changes in $\beta$ occur in practice as budget constraints become binding. For example, before July 2012 $\beta=0.7$ in Spain. At that time, the Spanish government enacted a law such that the replacement rate remained at $70 \%$ only for the first 6 months of being unemployed, but from then on decreased from 60 to $50 \%$ (up to a maximum of 24 months). This constituted a change in $\beta$ resulting from increased $u$ and falling tax revenue ( $t$ remained constant). See http://www.fedeablogs.net/economia/?p=23617.

7 Note that fixed beliefs about the level of $t^{*}$ could be introduced here in the form of a constant on the left hand side, but, as noted above, we exclude fixed beliefs from the model for the sake of simplicity as their inclusion here would not change the predictions of the model we are interested in.
} 
other-regarding $\left(\theta_{i}\right)$ is unobservable as is $I A$. Our strategy therefore is to control for the risk of unemployment, $p_{i}$, and thus the insurance motive (risk aversion) by exploiting an institutional feature of the Spanish labour market.

In Spain, most public sector workers hold civil servant status. These workers, known as funcionarios, hold life-long appointments and are thus shielded from the vagaries of the labour market. ${ }^{8}$ This institutionalised job security can be used to hold the insurance motive for redistribution via unemployment benefits constant, as these workers face almost no risk of unemployment, i.e. $p \approx 0$ and $\varepsilon_{p, u} \approx 0$. Given this feature of the Spanish labour market, we consider two cases from the above framework:

Case I: Private sector worker $\left(p_{i}>0, \varepsilon_{p_{i}, u}^{i}>0, \theta_{i} \geq 0\right)$

These workers face a positive probability of becoming unemployed, $p_{i}>0$, and this probability is a function of exogenous economic conditions, i.e. the unemployment rate, so $\varepsilon_{p_{i}, u}^{i}>0$. As we cannot observe $\theta_{i}$, if we estimated $\left.\frac{\mathrm{d} t^{*}}{\mathrm{~d} u}\right|_{\text {private }}>0$, we would not be able to conclude anything about the underlying motives. As suggested above, to disentangle the motives, we must hold one of them constant. We do this by considering the case of public sector workers.

Case II: Public sector worker $\left(p_{i} \approx 0, \varepsilon_{p_{i}, u}^{i} \approx 0, \theta_{i} \geq 0\right)$

These workers have little reason to demand redistribution as insurance as they enjoy a very high degree of, though not absolute, job security. Therefore, we would interpret a positive estimate of $\frac{\mathrm{d} t^{*}}{\mathrm{~d} u}$, as evidence of inequity aversion, i.e. $\theta_{i}>0$. Conversely, if $\left.\frac{\mathrm{d} t^{*}}{\mathrm{~d} u}\right|_{\text {public }}=0$, it would be consistent with the absence of inequity aversion, $\theta_{i}=0$, a conclusion that could be generalised to all workers under the restriction that $\left.\theta\right|_{\text {public }} \geq\left.\theta\right|_{\text {private }}$. We discuss this restriction in greater detail below.

\section{Data and estimation}

\subsection{Data}

We use survey and administrative data from Spain. Spain is an ideal setting for our study as unemployment benefits are homogenous across the country, labour mobility is low (Bentolila and Jimeno 1998), and unemployment benefits are tied directly to a particular tax in the form of social security contributions. In Spain, Social Security contributions are collected from earned income and this revenue must be used to fund unemployment benefits. This direct link arguably makes the cost of increasing unemployment benefits more salient as it would require an increase in Social Security contributions.

Information on individuals' declared preferences for public spending, including on unemployment benefits, as well as individual level socio-economic characteristics are taken from the 2005-2010 waves of the Centro de Investigaciones Sociológicas (CIS) survey. This annual survey in Spain is based on a nationally representative repeated cross section of 2500 individuals and focuses on subjective perceptions of the tax

\footnotetext{
8 Although de jure funcionarios can be fired for insufficient performance (article 63, of the Law 7/2007, April 12th, Basic Statute of the Public Worker), de facto this is extremely rare (Sanchez-Motos 2007).
} 
system and publicly provided goods and services. Our interest is primarily in the stated preferences for spending on unemployment benefits by employed respondents, $50.4 \%$ of the full sample. Respondents who are retired, studying, unemployed or out of the labour force are excluded from the main analysis.

In addition to the socio-economic characteristics, we observe the municipality of residence for each individual in the sample. ${ }^{9}$ We add information at the municipal level including unemployment rates, population, mean income for municipalities with at least 1000 residents covering $98 \%$ of the population (detailed data are not available for the smaller municipalities). We also add information on crimes at the provincial level as these are not available at the municipal level. These data are collected from La Caixa and from the Instituto Nacional de Estadística (INE) in Spain. Comparable data are not available for Navarra and Pais Vasco and so these Autonomous Communities (ACs) are excluded from the analysis. We are left with a sample of 5,741 workers residing in 1,139 municipalities over 5 years.

Table 1 presents descriptive statistics for worker-level and municipal-level variables by sector of employment. In Panel A, we present the descriptive statistics for the workers, and in Panel B, we present these for the municipal-level data. In column (1), we present the means and standard deviations (in brackets) for private sector workers, and in column (2), we present the same for public sector workers. Though we are unable to identify those with funcionario status, and thus virtually inviolable job security, most public sector workers are in fact funcionarios. During the observed period, the share of public workers who are 'civil servants' (funcionarios, in Spanish) was about $60 \% .{ }^{10}$ However, it is important to note as well that even those that do not have funcionario status (that is, their labour relationship with the public sector is through a temporary or private contract) enjoy a higher degree of job security than workers in the private sector (Sanchez-Motos 2007). The final column shows the results of a $t$ test for the difference in the means with standard errors in brackets.

The first variable in Panel A of Table 1 (Prefers more UB) is our dependent variable. This dummy is based on a survey question on respondents' feeling about the current level of spending on unemployment benefits. The question allows for five possible (mutually exclusive) responses: 'too much', 'too little', 'just the right amount', 'unsure' and refusal to answer. ${ }^{11}$ We have excluded those who are unsure or refuse to answer (16\% of respondents).

\footnotetext{
${ }^{9}$ Spain has three levels on sub-national administration. There are 17 Autonomous Communities (analogous to US states) which nest 50 provinces (analogous to US counties) which nest 8119 municipalities.

10 See the 2013 data released by the Boletín Estadística del Personal al servicio de las Administraciones Públicas.

${ }^{11}$ In Spanish, the survey question reads as follows: "Como Ud. sabe, el Estado destina el dinero que en España pagamos en impuestos a financiar los servicios públicos y prestaciones de las que venimos hablando. Dígame, por favour, si cree que el Estado dedica demasiados, los justos o muy pocos recursos a cada uno de los servicios que le voy a mencionar." In English: "As you know, the state spends the money that we pay in taxes in Spain to finance public services and benefits about which we are speaking. Tell me, please, if you think the state spends too much, the right amount or too little on each of the services we will mention." One of the several publicly provided goods and services that is asked about is unemployment benefits.
} 
Table 1 Descriptive statistics, Spanish data from 2005-2010

\begin{tabular}{|c|c|c|c|}
\hline & (1) & (2) & (3) \\
\hline & \multicolumn{2}{|l|}{$\underline{\text { Sector }}$} & \multirow[b]{2}{*}{ Difference } \\
\hline & Private & Public & \\
\hline \multicolumn{4}{|l|}{ Panel A: individual characteristics } \\
\hline Prefers more $\mathrm{UB}^{d}$ & $\begin{array}{l}0.426 \\
(0.495)\end{array}$ & $\begin{array}{l}0.350 \\
(0.477)\end{array}$ & $\begin{array}{l}0.077 * * * \\
(0.017)\end{array}$ \\
\hline Unemployment risk $\left(\widehat{p}_{i}\right)$ & $\begin{array}{l}0.123 \\
(0.084)\end{array}$ & $\begin{array}{l}0.061 \\
(0.072)\end{array}$ & $\begin{array}{l}0.062 * * * \\
(0.003)\end{array}$ \\
\hline High school only ${ }^{d}$ & $\begin{array}{l}0.357 \\
(0.479)\end{array}$ & $\begin{array}{l}0.287 \\
(0.453)\end{array}$ & $\begin{array}{l}0.069 * * * \\
(0.016)\end{array}$ \\
\hline Post-High school $^{d}$ & $\begin{array}{l}0.210 \\
(0.408)\end{array}$ & $\begin{array}{l}0.537 \\
(0.499)\end{array}$ & $\begin{array}{l}-0.327^{* * *} \\
(0.014)\end{array}$ \\
\hline Married $^{d}$ & $\begin{array}{l}0.548 \\
(0.498)\end{array}$ & $\begin{array}{l}0.582 \\
(0.493)\end{array}$ & $\begin{array}{l}-0.034^{*} \\
(0.017)\end{array}$ \\
\hline Young child ${ }^{d}$ & $\begin{array}{l}0.446 \\
(0.497)\end{array}$ & $\begin{array}{l}0.477 \\
(0.500)\end{array}$ & $\begin{array}{l}-0.031 \\
(0.017)\end{array}$ \\
\hline Age & $\begin{array}{l}38.318 \\
(11.419)\end{array}$ & $\begin{array}{l}41.162 \\
(10.775)\end{array}$ & $\begin{array}{l}-2.844 * * * \\
(0.384)\end{array}$ \\
\hline Male $^{d}$ & $\begin{array}{l}0.598 \\
(0.490)\end{array}$ & $\begin{array}{l}0.514 \\
(0.500)\end{array}$ & $\begin{array}{l}0.084 * * * \\
(0.017)\end{array}$ \\
\hline Primary earner ${ }^{d}$ & $\begin{array}{l}0.671 \\
(0.470)\end{array}$ & $\begin{array}{l}0.740 \\
(0.439)\end{array}$ & $\begin{array}{l}-0.069 * * * \\
(0.016)\end{array}$ \\
\hline Homeowner $^{d}$ & $\begin{array}{l}0.136 \\
(0.342)\end{array}$ & $\begin{array}{l}0.150 \\
(0.357)\end{array}$ & $\begin{array}{l}-0.014 \\
(0.012)\end{array}$ \\
\hline \multicolumn{4}{|l|}{ Panel B: municipal characteristics } \\
\hline Municipal unemployment & $\begin{array}{l}0.084 \\
(0.037)\end{array}$ & $\begin{array}{l}0.090 \\
(0.038)\end{array}$ & $\begin{array}{l}-0.006^{* * *} \\
(0.001)\end{array}$ \\
\hline Municipal population & $\begin{array}{l}475.341 \\
(924.523)\end{array}$ & $\begin{array}{l}475.583 \\
(913.781)\end{array}$ & $\begin{array}{l}-0.242 \\
(31.367)\end{array}$ \\
\hline Foreign residents & $\begin{array}{l}783.454 \\
(621.540)\end{array}$ & $\begin{array}{l}792.640 \\
(558.409)\end{array}$ & $\begin{array}{l}-9.186 \\
(20.753)\end{array}$ \\
\hline Provincial crimes ('000) & $\begin{array}{l}87.597 \\
(113.156)\end{array}$ & $\begin{array}{l}87.250 \\
(112.746)\end{array}$ & $\begin{array}{l}0.347 \\
(3.845)\end{array}$ \\
\hline Mean municipal income (€`000) & $\begin{array}{l}17.367 \\
(5.847)\end{array}$ & $\begin{array}{l}17.293 \\
(5.910)\end{array}$ & $\begin{array}{l}0.074 \\
(0.199)\end{array}$ \\
\hline Workers & 5,741 & 1,139 & \\
\hline
\end{tabular}

The superscript $\left({ }^{d}\right)$ indicates that the variable is a dummy. The bracketed values are standard deviations in the first two columns and the standard error of the difference between the means in the third column. Asterisk indicates statistical significant difference between the mean value for the private sector and for the public sector according to the following schedule: $* * * 1 \%, * * 5 \%$ and $* 10 \%$ 
We define our dependent variable as equal to 1 if the respondent says 'too little' is spent on unemployment benefits and 0 otherwise. ${ }^{12}$ We take it as given that this means that they would prefer more money to be spent on unemployment benefits. We assume that respondents are aware of the mechanism through which unemployment benefits are funded (note that respondents are prompted at the time of the survey that greater expenditure is funded via taxation), that is we assume that respondents know that there is no costless increase in public spending.

The second variable in Panel A, 'unemployment risk', is an estimate of each worker's unemployment risk based on their labour market characteristics. It is, in effect, an estimate of a worker's idiosyncratic risk of unemployment, $p_{i}$, defined in Sect. 2. We estimate $p_{i}$ using the sample of employed individuals (those in Table 1) plus the sample of individuals who are unemployed but previously had worked (i.e. those eligible for benefits or who left their job wilfully, but not retired people or those out of the labour force). The CIS records the sector, occupation and industry for current jobs (if employed) and for previous jobs (if unemployed). We then estimate

$$
p_{i}=w_{i}^{\prime} \omega+\eta_{i}
$$

where $p_{i}$ is a dummy variable equal to 1 if $i$ is currently unemployed and 0 if $i$ is employed, $w$ is a vector of $i$ 's employment characteristics including occupation ${ }^{13}$, industry of employment ${ }^{14}$ and level of education all interacted with the sector of employment and year effects, $\omega$ is a vector of parameters to be estimated, and $\eta_{i}$ is a well-behaved error term. We estimate Eq. 6 via a probit and the predicted probabilities, $\widehat{p}_{i}$, constitute the 'unemployment risk' variable.

As can be seen in Table $1 \bar{p} \mid$ public $=0.06$, about half the figure for the private sector, meaning our estimate of unemployment risk is positive for public sector workers despite their relatively high degree of job security. With respect to Case II discussed at the end of Sect. 2, the data suggest that $p_{i}$ is greater than 0 , though closer to 0 than for those in the private sector. However, the data support the restriction that $\epsilon_{p, u}^{i} \approx 0$, as $\bar{p} \mid$ public is not sensitive to changes in $u$. Note that $\bar{p} \mid$ public and $\bar{p} \mid$ private are not the probabilities of transitioning to unemployment but are an unemployment rate. As such $\bar{p}$ overestimates the probability of transitioning to unemployment in a given period since we only observe the stock of unemployed people, not the flow (we do not know when they became unemployed). The important feature for our purposes is that $\bar{p} \mid$ public does not vary over time and $\bar{p} \mid$ private does. If $\bar{p}$ is increasing over time it suggests that an increasing number of people are transitioning to unemployment. If it is stable over time it suggest the probability of transitioning to unemployment has not changed. Figure 1 plots $\bar{p} \mid$ public and $\bar{p} \mid$ private as well as the national unemployment rate.

As the economy fell into recession and unemployment rose, $\bar{p} \mid$ private increased (positive changes each year) meaning the probability of a private sector worker transi-

\footnotetext{
12 We use a binary dependent variable defined in this way for expositional expediency. We also estimate a multiple outcome model as a robustness check though.

13 Based on the 1979 National Classification of Occupations.

14 Based on the two-digit National Classification of Economic Activities.
} 


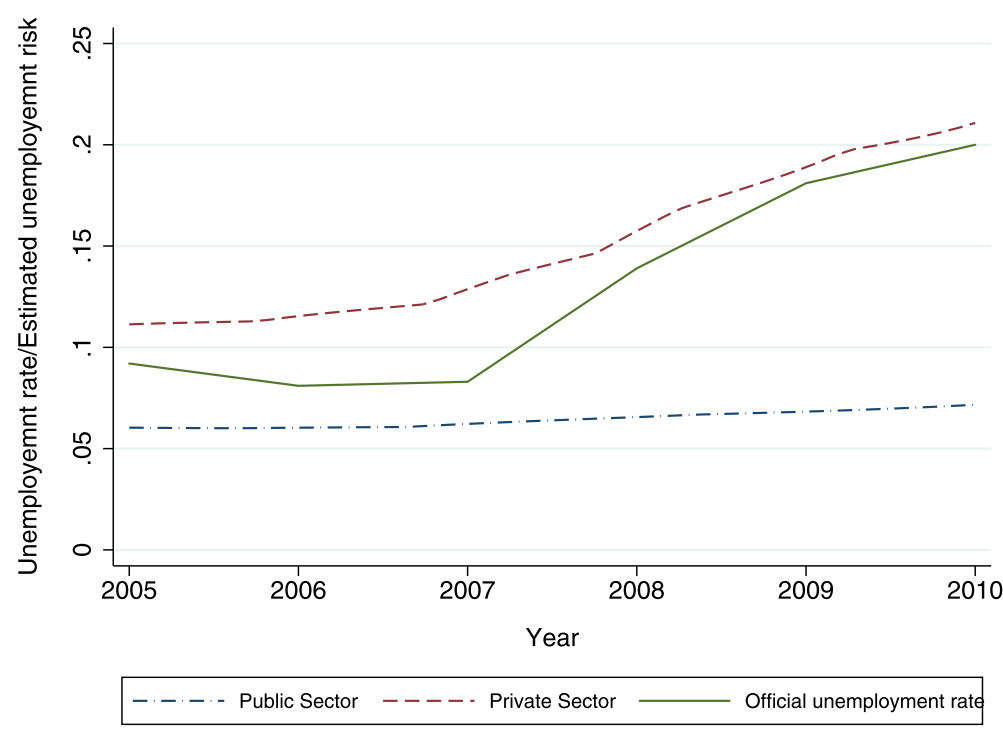

Fig. 1 National unemployment rate and unemployment risk $(\widehat{p})$ by sector over time. Notes: The official unemployment rate is obtained from the INE. The plots for the unemployment risk of the public and private sectors are based on predicted probabilities of transitioning to unemployment $(\hat{p})$ obtained using the CIS data

tioning to unemployment most likely increased as well. In the public sector, $\bar{p} \mid$ public changes very little, meaning the risk of transitioning to unemployment remains stable over the period i.e. $\varepsilon_{p_{i}, u} \approx 0$. Official employment statistics tell a similar story. ${ }^{15}$ Between 2008 and 2010, private sector employment fell $11 \%$, from 18.1 million to 16.1 million, whereas public sector employment actually grew slightly from 2.5 million to 2.6 million. ${ }^{16,17}$

As for the other individual-level characteristics (Panel A, Table 1), public sector workers are 3 years older on average, less likely to be male and more likely to be a household's primary earner. Public sector workers tend to be more educated. Public sector workers are also more likely to identify themselves as left-leaning politically.

\footnotetext{
15 Employment numbers were obtained from the INE.

16 We have also considered an alternative approach to identifying the funcionarios by assuming that funcionarios are over 30 years of age, working in the public sector administration and working in one of four occupations which we assumed to be most likely assigned funcionario status (no official mapping exists). The mean 'unemployment risk' for this arbitrarily defined group is indeed lower ( 0.04 vs 0.06 for all public sector workers taken together), and it also does not change over time.

17 Over this same period, there was a corresponding increase in the number of unemployed people in Spain from 2.6 million to 5.0 million. This strengthens our argument that $\hat{p}$, while not measuring the actual probability of transitioning to unemployment, is in fact consistent with, if not indicative of, the probability of transitioning from employment to unemployment. And that increase in $\hat{p}$ will thus be indicative of increases in the probability of transitioning to unemployment. Note that it is also true that higher values of $\hat{p}$ can result from increased unemployment duration. So, more generally $\hat{p}$ can be considered at the very least informative about individual exposure to the risk and duration of potential unemployment.
} 
In Panel B of Table 1, we consider the characteristics of the municipalities where the public and private sector workers reside. The first variable in Panel B is the municipal unemployment rate, our regressor of interest. On average, private sector workers live in municipalities with slightly lower (half a percentage point) rates of unemployment. Otherwise public and private sector workers do not live in systematically different municipalities, at least as measured by the characteristics presented here. Note that no measure of individual or household income, shown to be an important determinant of redistributive preferences (e.g. Alesina and Giuliano 2011), is reported in the CIS, so we use mean municipal income, obtained from tax records, as a proxy for household income (more on this below).

\subsection{Estimation}

Our analysis aims to determine the degree to which changes in the municipal unemployment rate drive changes in stated preferences for spending on unemployment benefits, other things being equal. To do so, we specify the following model of stated preferences for redistribution via unemployment benefits:

$$
\begin{aligned}
d_{i k t}= & x_{i k t}^{\prime} \beta_{1}+\pi_{i} x_{i k t}^{\prime} \beta_{1 \pi}+m_{k t}^{\prime} \beta_{2}+\pi_{i} m_{k t}^{\prime} \beta_{2 \pi} \\
& +\beta_{3} u_{k t}+\beta_{3 \pi} \pi_{i} u_{k t}+\beta_{4} \pi_{i}+e_{i k t}
\end{aligned}
$$

where $d_{i k t}$ is a dummy for worker $i$ in municipality $k$ at time $t$ which equals 1 if that worker believes 'too little' is spent on unemployment benefits, $\pi_{i}$ is a dummy equal to 1 if $i$ is employed in the public sector, $x_{i k t}$ is a vector of worker characteristics including age, gender, estimated 'unemployment risk' $\left(\hat{p}_{i}\right)$, a dummy for the presence of children in the household, marital status and a series of dummies controlling for home ownership distinguishing between a homeowner with no mortgage, a homeowner with partially paid mortgage, a renter and a residual 'other' category to help control for workers' mobility (discussed further below). $\beta_{1}$ is the corresponding vector of coefficients to be estimated, $m_{k t}$ is a vector of municipality $k$ 's characteristics at time $t$ including log population, the log number of foreign residents, as there is evidence to suggest that ethnic fractionalisation can affect redistributive preferences (Dahlberg et al. 2012) and the log mean income to help control for income as we do not observe individual level income (discussed further below). We also include the log number of crimes, though at the provincial level. $\beta_{2}$ is the corresponding vector of coefficients to be estimated, $u_{k t}$ is the unemployment rate in municipality $k$ at time $t, \beta_{3}$ is the impact of the local unemployment rate on stated preferences for unemployment benefits where $\beta_{3}$ is an analogue of $\partial t * / \partial u$, and $e_{i k t}$ is a composite error term with a fixed component, $\alpha_{i}$, and a random component, $\zeta_{i k t}$. Note that given this fully interacted specification $\beta_{j}^{\text {Private }}=\beta_{j}(j=1,2,3)$ is interpreted as the effect for private sector workers and $\beta_{j}^{\text {Public }}=\beta_{j}+\beta_{j \pi}$ as the effect for public sector workers. A formal test of whether the effect differs for the two groups is a simple $t$ test of $H_{0}: \beta_{j \pi}=0$.

The dependent variable is binary, and thus we might estimate Eq. 7 using a nonlinear limited dependent variable estimator such as a probit. Such estimators, however, require additional assumptions for consistency (e.g. homoskedasticity, see Greene 
2012, pp. 692-693) over and above those of OLS. We therefore estimate Eq. 7 as a linear probability model (via OLS) which can produce consistent estimates of the marginal effects in which we are interested (Angrist and Pischke 2009). We do check the robustness of our results to the use of a probit below.

Regardless of the estimator used, estimation of Eq. 7 and the interpretation of the results is complicated by four factors: the presence of fixed effects, possible geographical sorting by workers, potential omitted variable bias caused by unobserved income at the individual level and possible sorting into sectors on unobservables. First, there may be systematic regional differences in redistributive preferences. For example, regional social norms have been found to be important in the formation of redistributive preferences (Kuhn 2013). If these norms vary across regions, then we must control for them. To do so, we include AC fixed effects. We also include year fixed effects to control common shocks affecting the Spanish economy. This aids the identification of the effect of the unemployment rate rather than the effect of general macroeconomic changes that would correlate with the local unemployment rate.

A second issue is that workers may sort themselves geographically according to their level of human capital. Those with larger endowments of human capital are more mobile than others (Stambø1 2003) and may migrate towards the areas with better job opportunities, i.e. lower unemployment, such that the correlation between the level of human capital and local unemployment rates could be negative. Such individuals, those with more education, for example, have generally been found to prefer less redistribution (Alesina and Giuliano 2011) so $\frac{\text { aredistribution }}{\text { dHuman capital }}<0$. As a result, OLS estimates of $\beta_{3}$ may be positively biased. However, while such sorting may be a concern in theory, we note above that internal labour mobility in Spain is in fact very low (Bentolila and Jimeno 1998) so it is less likely to be a problem in our setting. Even so, we include the homeownership status of individuals as a regressor the argument being that homeowners are less mobile and thus are less likely to have migrated for work. We also estimate the model using only workers who own their own homes as a robustness check.

Third, a further bias may result from the fact that we do not observe $i^{\prime} s$ income. Income is a key variable in determining demand for redistribution in Meltzer-Richard model (Meltzer and Richard 1981), though empirical results have been mixed. Some find little evidence of income forming redistributive preferences (Fong 2001; Corneo and Grüner 2002) while others (Alesina and Giuliano 2011) find that it is important. By the Meltzer-Richard model, we expect $\frac{\text { aredistribution }}{\text { dincome }}<0$, i.e. higher income earners will tend to prefer less redistribution. We further expect a negative correlation between individual income and local unemployment rate, as higher rates of unemployment will exert downward pressure on wages (Blanchflower and Oswald 1994). Therefore OLS estimates of $\beta_{3}$ may be positively biased. We attempt to mitigate this bias by including the mean income in each municipality, though within municipality variation will clearly still remain. We further control for a number of individual characteristics correlated with income and potentially redistributive preferences (age, education, gender, occupation and industry of employment) though the omission of individual income will negatively bias the coefficient on 'unemployment risk'.

Lastly, differences between public and private sector workers could complicate the interpretation of our results. We adopt an estimation strategy where employment 
in the public sector might be conceived of as the 'treatment' and our interest is in whether the treatment changes how the unemployment rate affects stated redistributive preferences. However, this 'treatment' is, of course, not randomly assigned. Selection into one sector or another will be the function of any number of factors, many of which will be unobservable. Therefore, we cannot consider the sector of employment as a random, or even as a conditionally random, 'treatment'. This selection into sectors will be problematic if workers sort into those sectors based on relevant unobservable characteristics such as the degree to which they are 'pro-social' or 'other-regarding' $(\theta)$. Such selection will limit any claims we might make about causality, but it may not render the qualitative conclusions we draw from the sign and significance of results. As we are not able to model selection into the sectors explicitly for lack of an identifying instrument, we must then carefully consider the direction of the potential selection biases.

The existing evidence on the relative magnitudes of $\theta$ for public and private sector workers is mixed. Some studies have found public sector workers to be more prosocial/other-regarding (larger $\theta$ ) than private sector workers (Houston 2000; Banuri and Keefer 2013) which seems consistent with greater concern for redistribution, i.e. $\theta^{\text {Public }}>\theta^{\text {Private }}$. Tonin and Vlassopoulos (2014), however, find no difference in pro-sociality between sectors, i.e. $\theta^{\text {Public }}=\theta^{\text {Private }}$. We have no direct measure of $\theta$ in our data, though public sector workers are more likely to self-identify as politically left-leaning, the end of the political spectrum traditionally associated with greater support for redistribution (Alesina and Giuliano 2011). We are not aware of any study providing evidence consistent with $\theta^{\text {Public }}<\theta^{\text {Private }}$.

Given the existing evidence, we assume $\theta^{\text {Public }} \geq \theta^{\text {Private }}$ so that selection into the public sector produces a positive bias in estimates of $\beta_{3}^{\text {public }}$ and selection into the private sector produces a negative bias in estimates of $\beta_{3}^{\text {private }}$. Thus, our estimates of $\beta_{3}^{\text {public }}$ can be seen as an upper bound and of $\beta_{3}^{\text {private }}$ as a lower bound.

\section{Results}

We present our main results in Table 2, estimating the model using employed individuals. All estimates presented in Table 2 are obtained via OLS, and standard errors are clustered at the municipal level. In column (1), we present the results obtained from estimating the model for all workers while interacting all the regressors with a dummy equal to 1 if $i$ is employed in the public sector in period $t$ (see Eq. 7). We return to columns (2) and (3) below.

The marginal effect (calculated at the mean characteristics) of being in the public sector is -0.05 ( $p$ value $=0.013)$, indicating that public sector workers are, on average and ceteris paribus, about $6 \%$ points less likely to support increased unemployment benefits spending than their private sector counterparts. ${ }^{18}$

\footnotetext{
18 Note that this marginal effect is complicated by the fact that the sector of employment also appears in the estimation of $\hat{p}$ in equation (6). The overall marginal effect of being in the public sector is equal to $\frac{\partial d}{\partial \hat{p}} \frac{\partial \hat{p}}{\partial \pi}+\frac{\partial d}{\partial \pi}$. Combining these yields an overall effect of being in the public sector -0.06 . However,
} 
Table 2 Main results

\section{(1)}

(2)

(3)

\begin{tabular}{|c|c|c|c|}
\hline \multirow{3}{*}{ Unemployment risk } & \multicolumn{3}{|c|}{ Interacted with risk } \\
\hline & $0.747 * * *$ & 0.044 & -0.017 \\
\hline & -0.182 & $(0.372)$ & $(0.370)$ \\
\hline \multirow[t]{2}{*}{ Public $\times$ risk } & $-0.601 *$ & $-0.675^{* *}$ & -0.286 \\
\hline & -0.335 & $(0.326)$ & $(0.364)$ \\
\hline \multirow[t]{2}{*}{ Unemployment rate } & $1.279 * * *$ & 0.060 & 0.045 \\
\hline & -0.405 & $(0.581)$ & $(0.579)$ \\
\hline \multirow[t]{2}{*}{ Public $\times$ unemployment } & $-1.625 * *$ & & \\
\hline & -0.765 & & \\
\hline \multirow[t]{2}{*}{ Risk $\times$ unemployment } & & $6.852 * *$ & $7.479 * *$ \\
\hline & & $(3.154)$ & $(3.141)$ \\
\hline \multirow[t]{2}{*}{ Risk $\times$ public $\times$ unemployment } & & & $-6.359^{*}$ \\
\hline & & & $(3.575)$ \\
\hline \multirow[t]{2}{*}{ Public (at mean characteristics) } & $-0.054 * *$ & $-0.055^{* *}$ & $-0.056^{* *}$ \\
\hline & $(0.023)$ & $(0.023)$ & $(0.023)$ \\
\hline Workers & 5,741 & 5,741 & 5,741 \\
\hline$R^{2}$ & 0.045 & 0.042 & 0.043 \\
\hline
\end{tabular}

The dependent variable in the main equation is a dummy equal to 1 if the respondent believes 'too little' is spent on unemployment benefits and 0 otherwise. Bootstrapped standard errors (in brackets) are clustered at the provincial level. Asterisk indicates statistical significance according to the following schedule: *** $1 \%, * * 5 \%$ and $* 10 \%$. Individual controls, municipal level controls and both year and AC fixed effects are included in all models

The coefficient on 'unemployment risk' $(\beta=0.75, p$ value $<0.000)$ indicates that private sector workers facing greater 'unemployment risk' are more likely to support increased spending on unemployment benefits. The coefficient on the interaction term of public sector worker and 'unemployment risk' is negative $(\beta=-0.60)$ and statistically significant, though only at the $10 \%$ level ( $p$ value $=0.073$ ), indicating that the effect of risk differs for public and private sector workers. The effect of this risk for public sector workers is close to zero $(\beta=0.75+(-0.60)=0.15)$ and not statistically significant $(p$ value $=0.622) .{ }^{19}$

Similar variation over public and private sector workers is present in the effect of the local unemployment rate. The effect is positive $(\beta=1.28)$ and statistically significant ( $p$ value $=0.002$ ) for private sector workers. This suggests that increases

\footnotetext{
Footnote 18 continued

we are unable to compute standard errors for this effect as $\frac{\partial \hat{p}}{\partial r}$ and $\frac{\partial d}{\partial \hat{p}}, \frac{\partial d}{\partial r}$ come from different models using different regressors and different samples (employed and unemployed versus only the employed, respectively). As such we cannot obtain estimates of the standard error of the linear combination of the effects. Given this lack of standard error and as the full and partial effects are very similar, we report the partial effect in the tables of results.

19 Results are unaffected by using the alternatively identified funcionarios (see fn 16) instead of all public sector workers.
} 


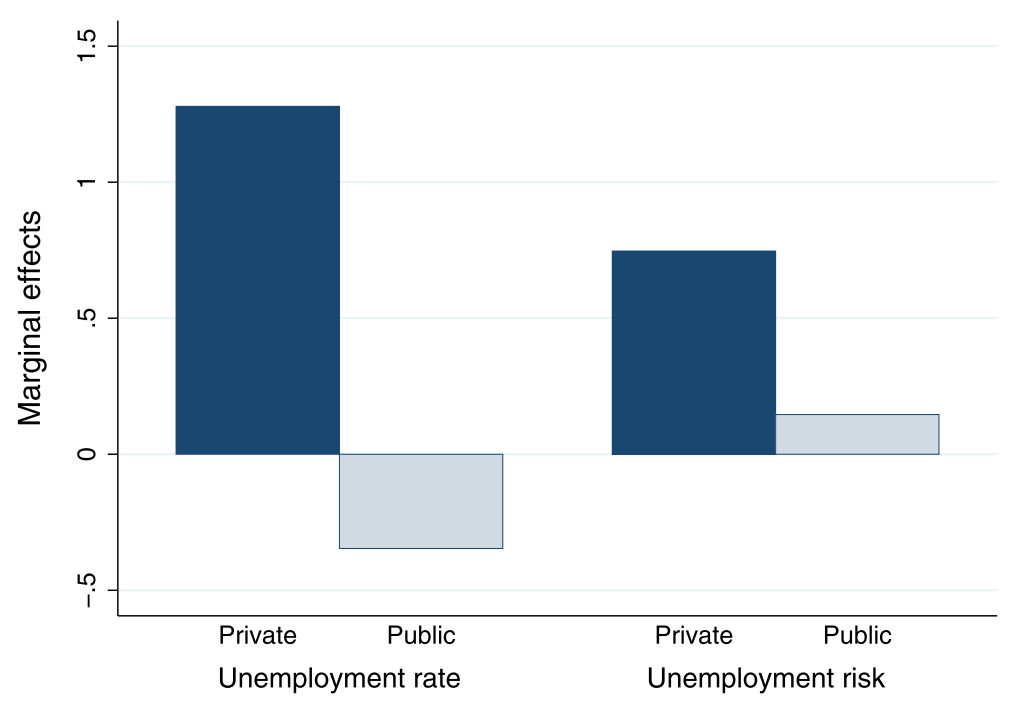

Fig. 2 The marginal effects of 'unemployment risk' and the unemployment rate for private and public sector workers. Notes: The left most bar is the estimated marginal effect of a change in the unemployment rate on support for increased unemployment benefits by private sector workers. The dark bars differ from 0 at the $5 \%$ level, light coloured bars do not differ from 0 at even the $10 \%$ level

in the unemployment rate lead to increases in a private sector worker's support for more spending on unemployment benefits. The interaction of the unemployment rate and the public sector is also significantly different from 0 ( $p$ value $=0.034)$, indicating that there is a significant difference in the effect between private and public sector workers. For public sector workers, the effect $(\beta=1.28+(-1.63)=-0.35)$ is not statistically different from 0 ( $p$ value $=0.621)$. These results suggest that while increases in the local unemployment rate lead those working in the private sector to prefer increased spending on unemployment benefits, the stated preferences of those enjoying the relative job security of the public sector do not change.

We summarise our main results graphically in Fig. 2 which shows the marginal effects outlined above. The dark bars are the marginal effects for those working in the private sector, both of which are statistically different from 0 at the $5 \%$ level. The light bars are the marginal effects for those in the public sector, neither of which are statistically different from 0 . Our main result suggests that changes in the local unemployment rate do affect the stated preferences for spending on unemployment benefits, but only for private sector workers, i.e. those workers with an insurance motive. In the absence of this motive, i.e. for public sector workers, changes in the local unemployment rate do not affect stated preference for redistribution via unemployment benefits.

We test the robustness of these results in a number of ways and present the results from these checks in Table 3. In column (1), we re-estimate the fully interactive model but include provincial rather than AC fixed effects. ${ }^{20}$ The effect of the unemployment rate and the difference in the effect for public and private sector workers maintains.

\footnotetext{
20 While there are more provinces, and thus the fixed effects will capture more of the variation in unemployment rates, provinces are purely geographical units and do not have any administrative role.
} 


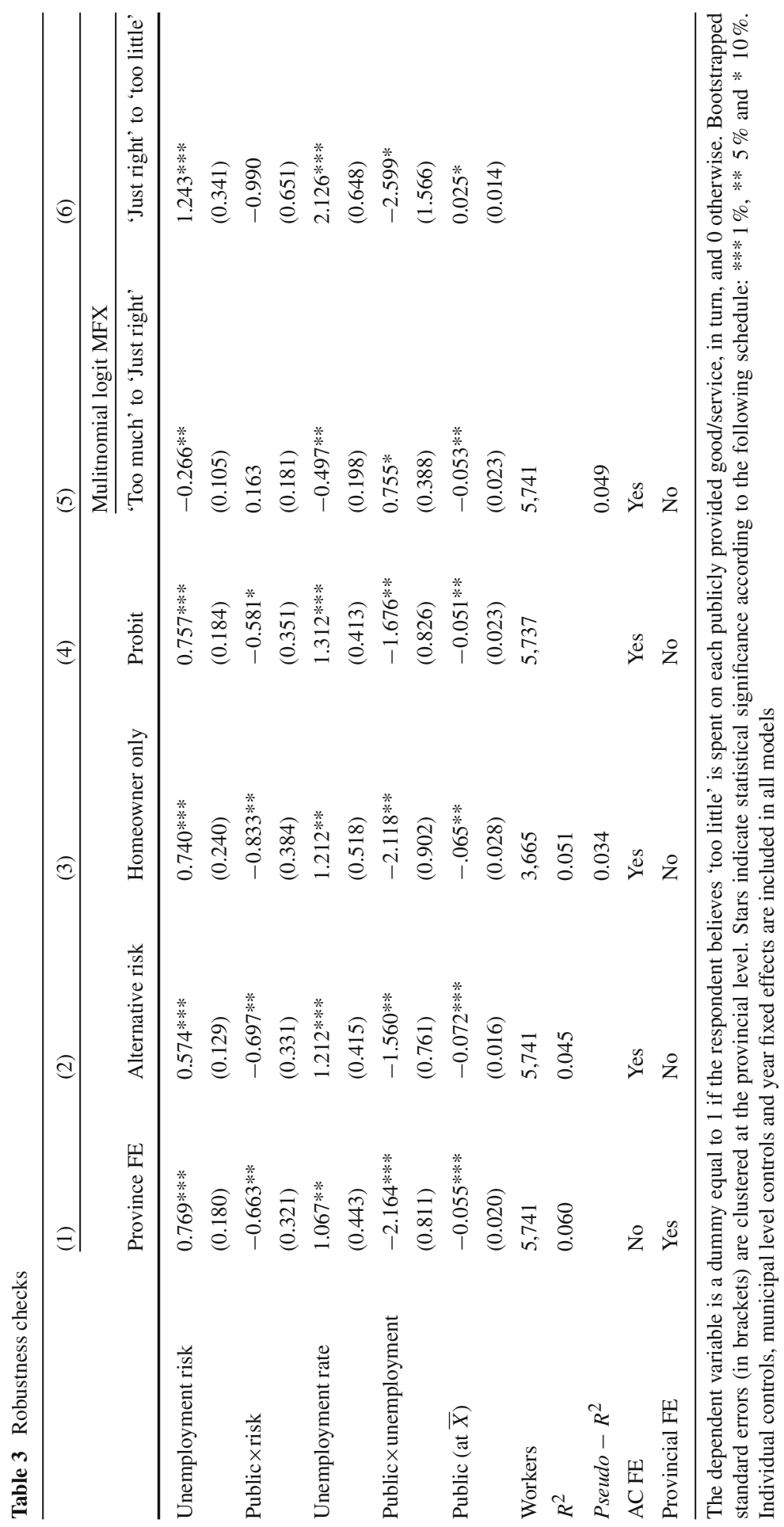


The effect of unemployment rates on the stated preferences of public sector workers is not statistically different from zero.

Given the importance of the 'unemployment risk' variable in our model, we consider the robustness of the result to an alternatively obtained $\hat{p}_{i}$. We re-estimate Eq. 6 using a fuller set of regressors including gender, age and province of residence in addition to the labour market characteristics used in the initial estimation of 'unemployment risk.' We use this new estimate of $\hat{p}_{i}$ and re-estimate our baseline model (results in column (2)). This alternative approach to estimating the 'unemployment risk' produces qualitatively similar results to those in column (1) of Table 2.

In column (3), we estimate the model using homeowners only as this is the subpopulation least likely to relocate and thus bias our results as discussed in Sect. 3.2. Again the results are stable. In column (4), we present the marginal effects from a probit estimator. The magnitude and significance of the effects are very close to those in Table 2. Results from a logit (not presented) were very similar to those in column (4).

In our primary analysis, we use a binary dependent variable equal to one if the respondent believes 'too little' is spent on unemployment benefits. This is based on a survey question with multiple responses however. We therefore use a multinomial logit and allow for three responses: 'too little', 'just right' and 'too much'. In columns (5) and (6), we present the marginal effects obtained from the multinomial logit where the reference group is that spending on unemployment benefits is 'just right'. The coefficients in column (5) are the effect of each variable on the probability of reporting 'just right' relative to reporting 'too much'. Here the coefficient on the local unemployment rate is negative as higher rates of unemployment reduce the probability a respondent believes 'too much' is spent on unemployment benefits relative to reporting that unemployment benefits spending is 'just right'. The effect for public sector workers $(\beta=-0.50+(0.76)=0.26)$ is not statistically different from zero ( $p$ value $=0.512)$. In column $(7)$, the coefficients are the effect on the probability of believing 'too little' is spent relative to the unemployment benefits spending being 'just right'. The results are again consistent with the unemployment rate increasing demand for unemployment benefits spending by private sector workers and not affecting the stated preferences of public sector workers.

We also carry out 'placebo tests' as it may be the case that private sector workers generally favour increased public spending in an effort to stimulate economic growth and thus improve their job prospects and reduce the risk that they become unemployed. In this case, the change in declared preferences for increased spending on unemployment benefits would not necessarily reflect an increase in the demand for insurance, but rather an increased demand for public spending in general. The CIS survey asks respondents for their view not only on unemployment benefits spending but also on a number of other public goods. We model preferences for spending on each of these. We generate a series of dummies which take a value of one if the respondent thinks 'too little' is spent on four other publicly provided goods/services: health, education, the justice system, policing and infrastructure. We then replace our primary dependent variable with these dummies and re-estimate the model, excluding in each case respondents who refuse to answer as we do in the primary analysis. Results are presented in Table 4. 
Table 4 Placebo tests

\begin{tabular}{llllll}
\hline & $(1)$ & $(2)$ & $(3)$ & $(4)$ & $(5)$ \\
\cline { 2 - 6 } & Health & Education & Justice & Security & Infrastructure \\
\hline Unemployment risk & -0.126 & -0.326 & -0.199 & -0.092 & -0.034 \\
Public $\times$ risk & $(0.223)$ & $(0.234)$ & $(0.215)$ & $(0.198)$ & $(0.129)$ \\
& $-0.650^{*}$ & -0.171 & 0.015 & -0.025 & -0.260 \\
Unemployment rate & $(0.389)$ & $(0.453)$ & $(0.411)$ & $(0.389)$ & $(0.234)$ \\
Public $\times$ Unemployment & -0.259 & 0.191 & -0.418 & -0.432 & 0.432 \\
\multirow{2}{*}{ Public $($ at $\bar{X})$} & $(0.473)$ & $(0.468)$ & $(0.482)$ & $(0.445)$ & $(0.264)$ \\
& 0.581 & $-1.578^{*}$ & -0.655 & -0.356 & -0.247 \\
Workers & $(0.821)$ & $(0.855)$ & $(0.887)$ & $(0.841)$ & $(0.555)$ \\
$R^{2}$ & -0.015 & $0.048^{* *}$ & 0.012 & 0.018 & -0.006 \\
\hline
\end{tabular}

The number of observations varies as we condition inclusion in these models on being included in the sample used in our primary estimation in Table 2 to ensure we are starting with the same base sample and then exclude those who are unsure or refuse to answer in each case. The dependent variable is a dummy equal to 1 if the respondent believes 'too little' is spent on each publicly provided good/service, in turn, and 0 otherwise. Bootstrapped standard errors (in brackets) are clustered at the provincial level. Stars indicate statistical significance according to the following schedule: *** $1 \%, * * 5 \%$ and $* 10 \%$. Individual controls, municipal level controls and both year and AC fixed effects are included in all models

The impact of the unemployment rate and of 'unemployment risk' on stated preferences for the public provision of these other goods/services is insignificant at the $5 \%$ level in every case. The coefficients on the interaction terms for public sector workers and unemployment risk are significant at the $10 \%$ level for health care spending (column 1) as is the coefficient on the interaction term for public sector workers and the unemployment rate for Education spending (column 2). However, in neither case is the total effect for public sector workers found to be statistically different from 0 . These results suggest that we are measuring a particular relationship between the unemployment rate and stated preferences for unemployment benefits and not a more general relationship between the state of the economy and preferences for public expenditure.

We next extend the analysis allowing the effect of changes in the local unemployment rate vary not just between the public and private sector workers but more generally with the degree of 'unemployment' risk.

Our primary analysis exploits a peculiarity of the Spanish labour market whereby many public sector workers enjoy virtually inviolable job security. But some private sector workers may also enjoy a high degree of job security. The argument put forth in the Sect. 2 can be applied to private sector workers with a high degree of job security. That is, we can relax the dichotomy assumed until now (that public sector workers have job security and private sector workers do not) and allow the job security to vary over individuals. To do so, we allow the effect of the local unemployment rate to vary with the individual 'unemployment risk' faced by an individual. We expect the 
stated preferences for unemployment spending of those workers facing higher levels of 'unemployment risk' will be more responsive to changes in the local unemployment rate.

To test this, we include a further regressor which is the interaction of the municipal unemployment rate and $\hat{p}_{i}$ from Eq. 6 and, additionally, the sector of employment. Results are presented in the last columns (2) and (3) of Table 2. In column (2), we include an additional interaction between the 'unemployment risk' variable and the municipal unemployment rate. The coefficient on this new interaction term is positive and statistically significant ( $p$ value $=0.030$ ) suggesting that the impact of the unemployment rate on demand for unemployment benefits spending is larger for those workers at greater risk of losing their jobs.

This model, however, may be overly restrictive in that it forces the interaction of 'unemployment risk' and the local unemployment rate to be the same for public and private sector workers. To relax this, we introduce a further interaction between the local unemployment rate, 'unemployment risk' and the dummy for public sector workers in column (3). The coefficients on the interaction terms are both statistically significant at the $10 \%$ level. At the mean 'unemployment risk' for private sector workers $(\bar{p}=0.123)$, the effect of local unemployment for private sector workers is statistically significant 0.97 ( $p$ value $=0.006$ ) and is increasing in 'unemployment risk.' For public sector workers, however, the effect of the local unemployment rate (calculated at the mean of 'unemployment risk' for public sector workers, $\bar{r}=0.061$ ) is 0.11 and is not statistically different from zero ( $p$ value $=0.808$ ).

The stated redistributive preferences of those private sector workers in industries and occupations with less job security are more sensitive to changes in the local unemployment rate than those with more secure jobs. Such variation is not present for public sector workers since, even those workers in relatively less secure industries and occupations, enjoy the relative security of being in the public sector. This result reinforces the implications of the primary analysis and is consistent with the theoretical framework outlined in Sect. 2.

\section{Conclusion}

The redistribution of wealth is one of the primary activities of the public sector, controversial though it may be. The reasons why people demand such redistribution even when they are net payers into the system are not fully understood. Studying redistributive preferences with respect to a particular instrument (unemployment benefits in this case) rather than in general might lead to more refined understanding of how those preferences are formed and expressed. In this paper, we have set out to test the motivations underlying individuals' stated preferences for one form of redistribution, unemployment benefits, and explore the extent to which support for redistribution is due to inequity aversion or risk aversion (demand for insurance). To do so, we use data on workers in Spain, a country with an institution of near inviolable job security for public sector workers.

We have shown that changes in the local rate of unemployment have a significant and economically relevant effect on workers' stated preferences for spending on 
unemployment benefits. We attempt to empirically disentangle the roles of demand for insurance and inequity aversion in forming preferences for redistribution. We find support for an insurance motive but no evidence of inequity aversion. From an economic point of view, it is important to know whether individual preferences for redistribution via unemployment benefits incorporate inequity aversion as well as risk aversion as failure to account for such motives may lead to an 'under-provision' of redistribution. The absence of evidence for inequity aversion has implications for the conception of redistribution, via this particular instrument, as a public good (Pauly 1973; Dorsch and Graham 2009). Therefore, the identification of the motive underlying redistributive preferences is more than an academic exercise but can have policy implications as well.

It is important to note that while the results are consistent with the dominance of the insurance motive in determining preferences for redistribution via unemployment benefits, we cannot readily generalise to all redistributive instruments. It may be true that individuals view unemployment benefits as a type of insurance while the purely redistributive role of those benefits goes under-appreciated by workers. Our results do not mean that all forms of redistribution are viewed as equal and that inequity aversion does not drive demand for other forms of redistribution (e.g. food stamps, progressive income tax, social housing). The evidence presented here suggests the absence of inequity aversion underlying demand for redistribution via unemployment benefits. However, others have found evidence of inequity aversion, in some form, underlying demand for redistribution in general (e.g. Corneo and Grüner 2002). We hope our result motivates future work focusing on the formation of redistributive preferences with respect to particular redistributive instruments rather than preferences for redistribution in some general sense to gain deeper insight into the complex nature of redistributive preferences.

Acknowledgements The authors are grateful to Sasha O. Becker, Johannes Becker, José Manuel CasadoDíaz, Mercè Costa, Maria Cubel, Vilen Lipatov, Rosina Moreno, Sendhil Mullainathan, Jorge Navas, Ana Nuevo, Amedeo Piolatto, Javier Romaní, Ignacio Ruiz-Conde, Santi Sanchez-Pages, Albert Solé-Ollé, Sara Torregrosa-Hetland, seminar participants at BIG, the Workshop on Federalism and Regional Policy at the University of Siegen, the CEA Conference, the RES Conference and the University of Alicante as well as the editor of ITAX, Prof. Andreas Haufler, and two anonymous referees for invaluable comments. We are also grateful to Angela Mediavilla for superb research assistance. Finally, we acknowledge funding from ECO2015-63591-R (MINECO/FEDER, UE), from the government of Catalonia (2014SGR420) and from the IEF. The usual disclaimer applies.

Open Access This article is distributed under the terms of the Creative Commons Attribution 4.0 International License (http://creativecommons.org/licenses/by/4.0/), which permits unrestricted use, distribution, and reproduction in any medium, provided you give appropriate credit to the original author(s) and the source, provide a link to the Creative Commons license, and indicate if changes were made.

\section{References}

Alesina, A., \& Giuliano, P. (2011). Preferences for redistribution. In Jess Benhabib, Alberto Bisin, \& Matthew O. Jackson (Eds.), Handbook of social economics (Vol. 1, pp. 93-131). Amsterdam: NorthHolland.

Angrist, J., \& Pischke, J.-S. (2009). Mostly harmless econometrics: An empiricist's companion. Princeton: Princeton University Press. 
Arrow, K. (1965). The theory of risk aversion. In: Yrjo Jahnssonin Saatio, Helsinki (Ed.), Aspects of the theory of risk bearing, reprinted in: Essays in the theory of risk bearing (pp. 90-109). Chicago: Markham Publ. Co. 1971,

Ashok, V., Kuziemo, I., \& Washington, E. (2016). Support for redistribution in an age of rising inequality: New stylized facts and some tentative explanations. Brookings Papers on Economic Activity, 2015, $367-433$.

Atkinson, A. B. (1970). On the measurement of inequality. Journal of Economic Theory, 2, 244.

Atkinson, A. B. (2015). Inequality: What can be done. Cambridge: Harvard University Press.

Banuri, S., \& Keefer, P. (2013). Intrinsic motivation, effort and the call to public service. World Bank Policy research working paper 6729.

Bentolila, S., \& Jimeno, J. (1998). Regional unemployment persistence (Spain, 1976-1994). Labour Economics, 5, 25-51.

Blanchflower, D., \& Oswald, A. (1994). The wage curve. Cambridge: MIT Press.

Boadway, R., \& Oswald, A. (1983). Unemployment insurance and redistributive taxation. Journal of Public Economics, 20, 193-210.

Boeri, T., Börsch-Supan, A., \& Tabellini, G. (2001). Would you like to shrink the welfare state? A survey of European citizens. Economic Policy, 16, 7-50.

Bover, O., Bentolila, S., \& Arellano, M. (2002). The distribution of earnings in Spain during the 1980s: The effects of skill, unemployment, and union power. In D. Cohen, T. Piketty y, \& G. Saint-Paul (Eds.), The economics of rising inequalities (pp. 3-53). Oxford: CEPR and Oxford University Press.

Casamatta, G., Cremer, H., \& Pestieau, P. (2000). Political sustainability and the design of social insurance. Journal of Public Economics, 75, 341-364.

Castells-Quintana, D., \& Royuela, V. (2012). Unemployment and long-run economic growth: The role of income inequality and urbanisation. Investigaciones Regionales, 24, 153-173.

Cooper, D., \& Kagel, J. (2013). Other regarding preferences: A survey of experimental results. In J. Kagel \& A. Roth (Eds.), The handbook of experimental economics, (forthcoming) (Vol. 2). Princeton: Princeton University Press.

Corneo, G., \& Grüner, H. (2002). Individual preferences for political redistribution. Journal of Public Economics, 83, 83-107.

Dahlberg, M., Edmark, K., \& Lundqvist, H. (2012). Ethnic diversity and preferences for redistribution. Journal of Political Economy, 120, 41-76.

De Donder, P., \& Hindricks, J. (2003). The politics of redistributive social insurance. Journal of Public Economics, 87, 2639-2660.

Dorsch, M., \& Graham, B. (2009). To give and get: Poverty alleviation as a local public good. Berlin: Mimeo.

Fehr, E., \& Schmidt, K. (1999). A theory of fairness, competition and co-operation. Quarterly Journal of Economics, 114, 817-868.

Fong, C. (2001). Social preferences, self-interest, and the demand for redistribution. Journal of Public Economics, 82, 225-246.

Gimpelson, V., \& Treisman, D. (2015). Misperceiving Inequality. NBER working paper no. 21174

Greene, W. H. (2012). Econometric analysis. Upper Saddle River: Prentice Hall.

Guillaud, E. (2013). Preferences for redistribution: An empirical analysis. Journal of Economic Inequality, $11,57-78$.

Houston, D. (2000). Public service motivation: A multivariate test. Journal of Public Administration Research and Theory, 10, 713-728.

Husted, T. (1990). Micro-based examination of the demand for income-redistribution benefits. Public Finance Review, 18, 157-181.

Kuhn, A. (2013). Inequality perceptions, distributional norms, and redistributive preferences in East and West Germany. German Economic Review, 14, 483-499.

Kuziemko, I., Norton, M., Saez, E., \& Stantcheva, S. (2015). How elastic are preferences for redistribution? Evidence from randomized survey experiments. The American Economic Review, 105, 1478-1508.

Luttmer, E., \& Singhal, M. (2011). Culture, context, and the taste for redistribution. American Economic Journal: Economic Policy, 3, 157-179.

McCall, L., \& Kentworthy, L. (2009). Americans' social policy preferences in the era of rising inequality. Perspectives on Politics, 7, 459-484.

Meltzer, A., \& Richard, S. (1981). A rational theory of the size of government. Journal of Political Economy, 89, 914-927. 
Meyer, D., \& Meyer, J. (2005). Relative risk aversion: What do we know? Journal of Risk and Uncertainty, 31, 243-262.

Moene, K., \& Wallerstein, M. (2001). Inequality, social insurance, and redistribution. American Political Science Review, 95, 859-874.

Neustadt, I. (2011). Do religious beliefs explain preferences for income redistribution? Experimental evidence. CESifo Economic Studies, 57, 623-652.

OECD. (2008). Growing unequal? Income distribution and poverty in OECD countries. Paris: OECD Publishing.

Pauly, M. (1973). Income redistribution as a local public good. Journal of Public Economics, 23, $209-288$.

Piketty, T. (1995). Social mobility and redistributive politics. The Quarterly Journal of Economics, 110, 551-584.

Piketty, T. (1996). The politics of redistribution: recent developments and research perspectives. Berlin: Mimeo.

Rawls, J. (1971). A theory of justice. Cambridge: Belknap Press of Harvard University Press.

Rueda, D., \& Pontusson, J. (2010a). The politics of inequality: Voter mobilization and left parties in advanced industrial states. Comparative Political Studies, 43, 675-705.

Sanchez-Motos, E. (2007). Civil service salary system in Spain and recent reform trends. In Conference on civil service salary systems in Europe. Bucharest, Romania (unpublished).

Stambøl, L. (2003). Regional labour market mobility by education and income. Economic Survey, 2, $25-32$.

Tonin, M., \& Vlassopoulos, M. (2014). Are public sector workers different? Cross-European Evidence from elderly workers and retirees. IZA discussion papers 8238, Institute for the Study of Labor (IZA).

Zweifel, P. (2013). The division of labor between private and social insurance. In Georges Dionne (Ed.), Handbook of Insurance (pp. 1097-1118). New York: Springer. 